\title{
CLINICO-PATHOLOGICAL STUDY OF OCULAR SURFACE SQUAMOUS NEOPLASIA IN A TERTIARY CARE CENTRE OF WESTERN REGION OF NEPAL
}

\author{
Sushila Patel, ${ }^{1}$ Binita Bhattarai Pokharel, ${ }^{2}$ Anita Shah, ${ }^{3}$ Manita Sunam Godar, ${ }^{1}$ Saraswati Khadka Thapa ${ }^{4}$
}

\section{ABSTRACT}

\section{INTRODUCTION}

Ocular surface squamous neoplasia (OSSN) consists of a wide range of conjunctival and corneal lesions ranging from dysplastic lesions to invasive squamous cell carcinoma. In recent times, the incidence of OSSN seems to be on the rise, especially in developing countries. The present study was aimed to analyse demographic pattern, clinical characteristics, and histopathology findings of OSSN in a tertiary care centre of western region of Nepal.

\section{MATERIAL AND METHODS}

It was a retrospective study. We analyzed 94 cases of OSSN who presented to cornea department of Lumbini Eye Institute, Bhairahawa, Nepal over a period 1.5 years from $1^{\text {st }}$ July 2017 to $31^{\text {st }}$ December 2018 . All the patients with OSSN, detailed clinical history and examination were recorded. Lesions were excised with a $3 \mathrm{~mm}$ margin clearance and sent for histopathological examination.

\section{RESULTS}

Mean age of our patients with OSSN was $48.89 \pm 17.955$ years ranging from 17 to 85 years. There were $52(55.32 \%)$ male and $42(44.68 \%)$ female. Mean duration of presentation was $6.34 \pm 6.17$ months. A solitary nodule at the limbus was the commonest presentation. Right eyes were involved more than left eyes. Lesions were found most commonly on temporal site $52(55.32 \%)$ followed by nasal $36(38.30 \%)$. On histopathological examination benign lesions were found in 31 $(32.98 \%)$ eyes, preinvasive lesion in $50(53.19 \%)$ eyes and invasive lesions in $13(13.83 \%)$ eyes.

\section{CONCLUSION}

OSSN were seen more commonly in young adults with male predominance. Benign and pre invasive lesions are found more commonly than invasive lesions.

KEYWORDS Conjunctival intraepithelial neoplasm, demography, ocular surface squamous neoplasia, conjunctival squamous cell carcinoma.

1. Department of Cornea, Lumbini Eye Institute, Bhairahawa, Nepal

2. Department of Oculoplasty, Lumbini Eye Institute, Bhairahawa, Nepal

3. Department of Pathology, Universal College of Medical Sciences, Bhairahawa, Nepal

4. Research Coordinator, Lumbini Eye Institute, Bhairahawa, Nepal

DOI: https://doi.org/10.3126/jucms.v7i1.24677

For Correspondence

Dr. Sushila Patel

Department of Ophthalmology

Lumbini Eye Institute

Bhairahawa, Nepal

Email:drsushilapatel@yahoo.com 


\section{INTRODUCTION}

Ocular surface squamous neoplasia (OSSN) is a rare clinical entity. It is a broad term encompassing conjunctival intraepithelial neoplastic lesions (CIN) and invasive squamous cell carcinoma (SCC) of conjunctiva and cornea. The average incidence of OSSN of conjunctiva and cornea varies from $0.13 / 100,000$ to $3.5 / 100,000$ population. $^{1-3}$ In recent years, the incidence of OSSN is increasing in developing countries. OSSN is mostly unilateral and is seen in middle age and older adult patients. ${ }^{4}$ Risk factors associated with the development of OSSN are exposure to ultraviolet (UV)-B light, human immunodeficiency virus (HIV) infection, human papilloma virus (HPV) infection, cigarette smoking, chemicals such as trifluridine or petroleum products, ocular surface injury, vitamin A deficiency and Xeroderma Pigmentosum. ${ }^{5-7}$ Tumours of the ocular surface have a wide clinical presentation but are usually asymptomatic. OSSN is a low-grade, slow growing malignancy, which rarely metastasize. OSSN usually presents as an elevated conjunctival lesion seen at or near the limbus, grayish-white in colour with a characteristic tuft of blood vessels in the inter paplebral region.

A few patients may present with redness, irritation or foreign body sensation. It is nearly impossible to differentiate OSSN as benign or malignant based on clinical appearance so surgical excision and histopathological examination is always necessary to make correct diagnosis and management. As these tumours are relatively uncommon and data regarding these lesions are relatively scare form this part of the world so this study was planned to evaluate clinico-demographic characteristics, and histopathology finding of OSSN in a tertiary care centre of western region of Nepal.

\section{MATERIAL AND METHODS}

It was a retrospective study conducted on patients aged $>15$ years and presented to the department of cornea in Lumbini Eye Institute, Bhairahawa, Nepal over a period of 1.5 years

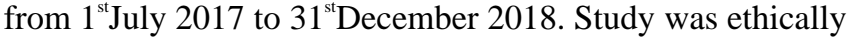
approved by the institutional review committee of Lumbini Eye Institute. All the subjects presented with OSSN during the study period were included in the study. We excluded patients $<16$ years of age. Patients of pterygium, pingecula and limbal dermoid were also excluded.

A detailed history including demographic data of age, sex, occupation, time of presentation, and exposure to risk factors known to cause OSSN were noted in all the patients. Adetailed clinical and slit lamp examination was performed to document clinical features of the tumours. High-resolution digital photographs were taken. Clinical features regarding the type of lesion, location and involvement of cornea were documented. Blood investigations like random blood sugar
(RBS), hepatitis B surface antigen (HBsAg) and HIV test were done after obtaining informed consent of the patients. Peribulbar block with $2 \%$ lignocaine was used for local anaesthesia. All lesions were excised by single surgeon with a 3-mm margin clearance, using the 'no touch technique' to minimise tissue handling. Carl Zeiss OPMI VISU 160 operating microscope was used for surgery. After excision tissue were placed directly into buffered formalin and sent for histopathology examinationat the histopathology laboratory of the Universal College of Medical Sciences, Bhairahawa, Nepal.

All the histology slides were stained with haematoxylin and eosin and examined by the same pathologist. All the data entered into Microsoft Excel spreadsheet and were analyzed using SPSS ver 16.0(PC) / EpiInfo (CDC, Atlanta, GA, USA). Statistical analysis was done using appropriate test like Chisquare test and a p-value of less than 0.05 was considered significant.

\section{RESULTS}

All together 94 patients were presented during the study period and were analyzed. There were $52(55.32 \%)$ male and $42(44.68 \%)$ female. Mean age of our patients was $48.89 \pm 17.95$ years ranging from 17 to 85 years. There were 51 $(54.26 \%)$ patients aged $=50$ years and $43(45.79 \%)$ patients aged $>50$ years. (Table 1$)$

Table 1. Age distribution

\begin{tabular}{ll}
\hline Age group & Frequency(\%) \\
\hline $16-20$ & $3(3.19 \%)$ \\
$21-30$ & $18(19.15 \%)$ \\
$31-40$ & $16(17.07 \%)$ \\
$41-50$ & $14(14.89 \%)$ \\
$51-60$ & $17(18.09 \%)$ \\
$61-70$ & $16(17.07 \%)$ \\
$71-80$ & $8(8.51 \%)$ \\
$81 \_90$ & $2(2.13 \%)$ \\
\hline
\end{tabular}

We had patients from both India and Nepal. There were 48 (51.06\%) patients from Nepal including Rupandehi (18), Palpa (6), Nawalparasi (5), Arghakhachi (4), Dang (4), Kapilvastu (4), Gulmi (3), Pyuthan (3) and Kanchanpur (1) districts. From India there were $46(48.94 \%)$ patients from state of Bihar and Uttar Pradesh. There were patients from Maharajgunj (10), Siddharthanagar (8), Deoria (6), Gorakhpur (4) Santa Kabir Nagar (4), Gazipur (3), Balrampur (2), Saran (2), Mau (2), Azamgarh (1), Gaya (1), Jaunpur (1), Kushinagar (1) and Siwan (1) districts. By occupation most of patients were farmer 42 (44.68), followed by housewife 39 (41.49\%) students 9 (9.57) and servicemen 4 (4.26\%), Mean duration of presentation was $6.34 \pm 6.17$ months ranging from minimum 1 month to maximum 36 months. History of trauma 
was found in only $8(8.51 \%)$ cases. In this series systemic illness was found in $8(8.51 \%)$ patients which included hypertension $3(3.19 \%)$ patients, diabetes mellitus $2(2.13 \%)$ patients, HIV $2(2.13 \%)$ patients and tuberculosis $1(1.06 \%)$ patients. Lesions were found more commonly in right eye 52 (55.32\%) followed by left eye in 42 (44.68\%).
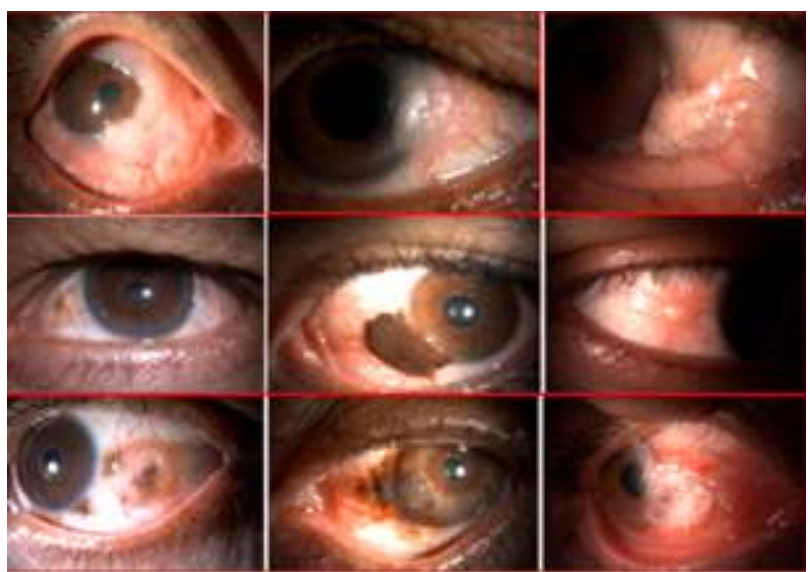

Figure 1. Some OSSN lesions of eye

Lesions were found most commonly on temporal side of the limbus $52(55.32 \%)$ followed by nasal side 36 (38.30\%), inferior side $3(3.19 \%)$, whole $2(2.13 \%)$ and superior part 1 $(1.06 \%)$ (Figure 1and 2).

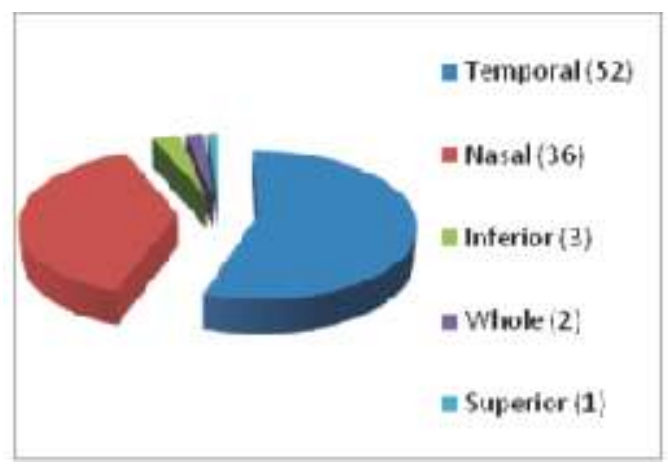

Figure 2. Site of OSSN lesions

On histopathological examination benign lesions were found in $31(32.98 \%)$ eyes, preinvasive lesion in $50(53.19 \%)$ eyes and invasive lesions in $13(13.83 \%)$ eyes. Among benign lesions squamous papilloma was found in $23(24.47 \%)$, epiderrmoid cyst in $4(4.26 \%)$, conjunctival nevus in 3 (3.19\%) and keratoacanthoma in $1(1.06 \%)$ eyes.

Preinvasive lesions were CIN I in $10(10.64 \%)$ eyes, CIN II 8 $(8.51 \%)$ eyes and CIN III $32(34.04 \%)$ eyes. Invasive squamous cell carcinoma was found in $9(9.57 \%)$ eyes and malignant melanoma in 4 (4.26\%) eyes of patients (Figure 3 ).

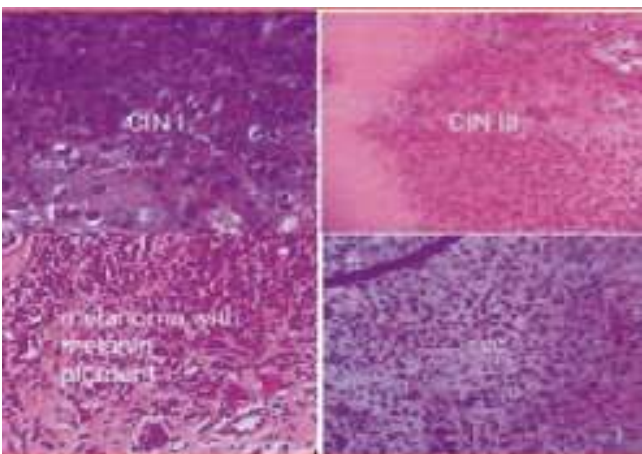

Figure 3. Histopathology of few OSSN lesions

\section{DISCUSSION}

OSSN sare seen more commonly in young adults. Mean age of our patients was 48.89 years ranging from 17 to 85 years which is similar to the study done by Dandala PP et. al. where the mean age of the patients was 45.20 years with age ranging from 18 to 78 years. ${ }^{8}$ In our study, there were $55.32 \%$ male so male outnumbered female which are seen in many other studies also. ${ }^{9-12}$ Higher incidence of OSSN in male gender and young adult age group may be associated with increased exposure to ultraviolet rays exposure during outdoor work. Prevalence of OSSN in Africa is higher in female than male. ${ }^{13-14}$ This may be related to Africa having the highest prevalence of both HIV and HPV, which may increase the risk of OSSN in women. By occupation most of patients (44.68\%) were farmers, followed by housewives $41.49 \%$ which is obvious as this is a agriculture predominant area where living of most of population are based on agriculture related work. These farmers also more exposed with UV lights during outdoor farming activities. Mean duration of presentation was 6.34 months ranging from minimum 1 month to maximum 36 months. In a study done in Delhi, mean duration of symptoms was 1.03 year. $^{12}$

The pathogenesis of OSSN is multifactorial. Various etiological factors are thought to be responsible for OSSN, but it is not clear how they interact and lead to development of OSSN. Factors associated with the development of OSSN are exposure to sunlight, HPV type 16 and 18 infections, HIV infection, ocular surface injury, chemicals such as trifluridine, arsenic, beryllium or petroleum products, vitamin A deficiency Xeroderma pigmentosum, old age, heavy cigarette smoking, male sex, immune-compromised states and light pigmentation of the hair and eye. All these factors lead to genetic injury to a proliferating cell which lead to uncontrolled basic cellular functions like cell division and differentiation and make them neoplastic. There is linear relationship between exposure to ultraviolet radiation and development of OSSN. The degree of risk depends on the type of UV rays, the intensity of exposure, duration of exposure and the quantity of 
the light-absorbing protective melanin in a person. Among UV rays, UV B is believed to be responsible for the induction of various cutaneous and ocular surface cancers. Exposure to UV $\mathrm{B}$ light leads to the formation of pyrimidine dimers in DNA and it also causes damage to the nucleotide excision repair pathway which plays a key role in repairing DNA damage. HPV is a DNA virus. HPV types 16 and 18 have been implicated in the genesis of several cancers, particularly squamous cell carcinoma of the cervix, anogenital, oropharyngeal and ocular surface regions. There is an increase in the incidence of OSSN, since the emergence of HIV. The rising incidence of OSSN in recent decades may be driven by increased prevalence of these. In this study, history of trauma was found in only $8.51 \%$ and HIV in $2.13 \%$ patients. These results are similar to study from Delhi where only one patient was found to have HIV. Studies especially from Africa have a higher incidence of HIV and HPV. In these countries OSSN are also found to occur more at younger age group. ${ }^{14,15}$ In a study done by Dandala et al. from Hyderabad, about $23 \%$ of the patients tested positive for HIV in whom mean age of presentation was 34 years only. ${ }^{8}$ OSSN lesions occur more often in the interpalpebral area of perilimbal conjunctiva, and can extend across the limbus to involve the cornea. Isolated corneal involvement by OSSN is very rare.

A study in Uganda demonstrated that tumors almost always occur in sun-exposed areas of the eye. ${ }^{16}$ It is thought that the human eye is more exposed laterally, making this a large collecting zone of peripheral sunlight. In our study lesions were found most commonly on temporal side $55.32 \%$ followed by nasal side $38.30 \%$ which is similar to another study where $50.44 \%$ had nasal lesions and $49.56 \%$ had temporal lesions. ${ }^{8}$ Clinical presentation of CIN and invasive SCC is very similar thus it is very difficult differentiate them clinically. Usually OSSN presents as a circumscribed, gelatinlike, sessile, papillomatous lesion with variable degrees of leukoplakia. One often finds dilated conjunctival blood vessels feeding and draining the lesion. SCC is locally invasive and metastasis is very rarely seen. Sometimes, OSSN can be diffuse, flat, and poorly-demarcated lesions without an obvious tumour, making early diagnosis difficult. Sometimes, lesions can be massive covering the entire ocular surface area or rarely pigmented which can be difficult to differentiate from conjunctival melanoma. Histopathological evaluation of the lesion after an excisional biopsy is the gold standard for the diagnosis of OSSN. CIN can progress to invasive SCC with destruction of the epithelial basement membrane and extension into the underlying stromal tissue. Differentiation of SCC is in terms of degree of keratinisation termed as welldifferentiated, moderately differentiated and poorly differentiated carcinoma. Keratinisation is seen more in well and moderately differentiated tumours with less nuclear pleomorphism. Poorly differentiated tumours have predominance of immature cells with higher nuclear- cytoplasmic ratio, more pleomorphic nuclei, increased typical and atypical mitoses and minimal keratinization. Other ocular surface lesions which can clinically mimic OSSN such as actinic keratosis, pterygium, pinguecula andactinic granuloma can be easily distinguished from OSSN by studying the morphology. Management modalities in OSSN range from complete excision in well delineated tumours to chemotherapy in diffuse unresectable lesions. Medical alternatives in the form of topical applications 5Fluorouracil (5FU), mitomycin C (MMC) and Interferon (IFNa2b) have been extensively reported in the literature. Primary treatment with chemo therapeutic agents for OSSN is largely limited to localized OSSN. Both MMC and 5FU have also been used as adjuvant therapy for recurrent lesions. ${ }^{17,18}$ Owing to a better toxicity profile of IFNa2bcurrently seems to be the treatment of choice for wider and extensive OSSN involving >4 clock hours of the limbus. ${ }^{19}$ The overall prognosis in OSSN is good. Modern treatment strategies are effective with local recurrence rates reported to be 5\% and regional lymph node metastasis at $<2 \%$. Aggressive variants like muco-epidermoid and spindle cell carcinoma and OSSN in immuno compromised patients have a worse prognosis. While complete excision with cryotherapy gives excellent results with localized lesions, newer modalities like immuno therapy hold a promise in the larger, un resectable and recurrent lesions.

\section{CONCLUSION}

OSSNs are seen more commonly in young adults with male predominance. Lesions are found most commonly on temporal side followed by nasal side which together make majority of lesions. Benign and preinvasive lesions are found more commonly then invasive lesions. Nodular type of lesion is the commonest variety. On histopathological examination among benign lesions squamous papilloma and among invasive lesions, invasive squamous cell carcinoma were the commonest diagnosis. So, all the OSSN lesions should be evaluated carefully and treated with proper excision with histopathological examination.

\section{ACKNOWLEDGEMENTS}

Authors are indebted to all our patients, the OT and OPD supporting staff of Lumbini Eye Institute, staff of Department of Pathology of Universal College of Medical Sciences who helped us in our study.

\section{CONFLICT OF INTERESTS}

Nil. 


\section{REFERENCES}

1. Templeton AC. Tumors of the eye and adnexa in Africans in Uganda. Cancer 1967;20:1689-98.

2. Lee GA, Hirst LW. Incidence of ocular surface epithelial dysplasia in metropolitan Brisbane. A 10-year survey. Arch Ophthalmol. 1992;119:525-7.

3. Sun EC, Fears TR, Goedert JJ. Epidemiology of squamous cell conjunctival cancer. Cancer Epidemiol Biomarkers Prev 1997;6: 73-7.

4. Lee GA, Hirst LW. Ocular surface squamous neoplasia. Surv Ophthalmol 1995;39:429-50.

5. Armstrong BK, Kricker A. The epidemiology of UV induced skin cancer. J Photochem Photobiol 2001;63:8-18

6. Basti S, Macsai MS. Ocular surface squamous neoplasia: a review. Cornea 2003;22:687-704.

7. Weinstein JE, Karp CL. Ocular surface neoplasias and human immunodeficiency virus infection. Curr Opin Infect Dis 2013;26 :58-65.

8. Dandala PP, Malladi P, Kavitha. Ocular Surface Squamous Neoplasia (OSSN): A Retrospective Study. J Clin Diagn Res. $2015 ; 9$ (11):NC10-3.

9. Kim BH, Kim MK, Wee WR, Oh JY. Clinical and pathological characteristics of ocular surface squamous neoplasia in an Asian population. Graefes Arch Clin Exp Ophthalmol. 2013;251: 2569-73.

10. Shields CL, Demirci H, Karatza E, Shields JA. Clinical survey of 1643 melanocytic and nonmelanocytic conjunctival tumors. Ophthalmology 2004;111:1747-54.

11. Chauhan S, Sen S, Sharma A, Tandon R, Kashyap S, Pushker N, et al. American joint committee on cancer staging and clinic opathological high-risk predictors of ocular surface squamous neoplasia: A study from a tertiary eye center in India. Arch Pathol Lab Med. 2014;138:1488-94.

12. Meel R, Dhiman R, Vanathi M, Pushker N, Tandon R, Devi S. Clinicodemographic profile and treatment outcome in patients of ocular surface squamous neoplasia. Indian J Ophthalmol. 2017;65(10):936-941.

13. Spitzer MS, Batumba NH, Chirambo T et al. Ocular surface squamous neoplasia as the first apparent manifestation of HIV infection in Malawi. Clinical \& Experimental Ophthalmology 2008;36: 422-425.

14. Ateenyi-Agaba C. Conjunctival squamous-cell carcinoma associated with HIV infection in Kampala, Uganda. Lancet 1995;345: 695-696.
15. Gichuhi S, Macharia E, Kabiru J, Zindamoyen AM, Rono H, Ollando E, Wanyonyi L, Wachira J, Munene R, Onyuma T, Sagoo MS, Weiss HA, Burton MJ. Clinical Presentation of Ocular Surface Squamous Neoplasia in Kenya. JAMA Ophthalmol. 2015 Nov; 133(11):1305-13.

16. Waddell KM, Downing RG, Lucas SB \& Newton R) Corneoconjunctival carcinoma in Uganda. Eye (London, England) 2006; 20:893-899.

17. Parrozzani R, Lazzarini D, Alemany-Rubio E, et al. Topical $1 \%$ 5-fluorouracil in ocular surface squamous neoplasia: a long-term safety study. Br J Ophthalmol 2011;95:355-9.

18. Shields CL, Demirci H, Marr BP, et al. Chemoreduction with topical mitomycin $\mathrm{C}$ prior to resection of extensive squamous cell carcinoma of the conjunctiva. Arch Ophthalmol 2005;123 :109-13.

19. Roy A, Rath S, Das S, Vemuganti GK, Parulkar G. Penetrating sclerokeratoplasty in massive recurrent invasive squamous cell carcinoma. Ophthal Plast Reconstr Surg 2011; 27: e39-40. 